\title{
Association of Pre-End-Stage Renal Disease Hemoglobin with Early Dialysis Outcomes
}

\author{
Carola-Ellen Kleine ${ }^{\mathrm{a}, \mathrm{b}}$ Melissa Soohoo ${ }^{\mathrm{a}-\mathrm{c}}$ Omesh N. Ranasinghe ${ }^{\mathrm{a}}$ \\ Christina Park ${ }^{a, b}$ Maria V. Marroquin ${ }^{a, b}$ Yoshitsugu Obi ${ }^{a}$ Connie M. Rhee ${ }^{a}$ \\ Hamid Moradia, ${ }^{a}$ Csaba P. Kovesdy ${ }^{d, e}$ Kamyar Kalantar-Zadeh ${ }^{a-c}$ \\ Elani Streja $a^{a, b}$
}

\begin{abstract}
a Harold Simmons Center for Kidney Disease Research and Epidemiology, Division of Nephrology and Hypertension, University of California Irvine, School of Medicine, Orange, CA, USA; ${ }^{\mathrm{b}}$ Tibor Rubin VA Medical Center, Long Beach,

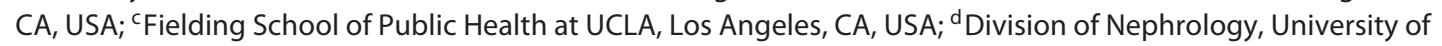

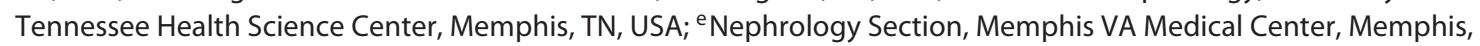
TN, USA
\end{abstract}

\section{Keywords}

End-stage renal disease $\cdot$ Hemoglobin · Anemia $\cdot$ Chronic kidney disease $\cdot$ Mortality

\begin{abstract}
Background: Incident hemodialysis patients have a high mortality risk within the first months after dialysis initiation. Pre-end-stage renal disease (ESRD) factors like anemia management may impact early post-ESRD outcomes. Therefore, we evaluated the impact of pre-ESRD hemoglobin $(\mathrm{Hgb})$ and pre-ESRD Hgb slope on post-ESRD mortality and hospitalization outcomes. Methods: The study included 31,472 veterans transitioning to ESRD. Using Cox and negative binomial regression models, we evaluated the association of pre-
\end{abstract}

\section{C.-E.K. and M.S. equally contributed to this study.}

\section{KARGER}

(c) 2018 S. Karger AG, Basel

E-Mail karger@karger.com

www.karger.com/ajn
ESRD Hgb and $\mathrm{Hgb}$ slope with 12-month post-ESRD all-cause and cardiovascular mortality and hospitalization rates using 4 levels of hierarchical multivariable adjustment, including erythropoietin use and kidney decline in slope models. $\boldsymbol{R} \boldsymbol{e}-$ sults: The cohort was $2 \%$ female, $30 \%$ African-American, and on average $68 \pm 11$ years old. Compared to Hgb $10-<11 \mathrm{~g} /$ $\mathrm{dL}$, both low $(<10 \mathrm{~g} / \mathrm{dL})$ and high $(\geq 12 \mathrm{~g} / \mathrm{dL}$ ) levels were associated with higher all-cause mortality after full adjustment (HR 1.25 [95\% Cl 1.15-1.35] and 1.09 [95\% Cl 1.02-1.18], respectively). Similarly, Hgb exhibited a U-shaped association with CV mortality, while only lower Hgb was associated with a higher hospitalization rate. Neither an annual pre-ESRD decline in Hgb nor increase was associated with higher postESRD mortality risk after adjustment for kidney decline. However, we observed a modest J-shaped association between 
pre-ESRD Hgb slope and post-ESRD hospitalization rate. Conclusions: Lower and higher pre-ESRD Hgb levels are associated with a higher risk of early post-ESRD mortality, while there was no association between the pre-ESRD slope and mortality. An increase in pre-ESRD Hgb slope was associated with higher risk of post-ESRD hospitalization. Additional studies aimed at anemia management prior to ESRD transition are warranted.

(c) 2018 S. Karger AG, Basel

\section{Introduction}

Anemia, a commonly observed condition in patients with chronic kidney disease (CKD), is strongly related to poorer outcomes, such that prior studies have demonstrated its relationship with higher risk of all-cause and cardiovascular (CV) mortality, as well as hospitalization [1-3]. The prevalence of anemia progressively increases with the severity of CKD, ranging from $27 \%$ in stage $1 / 2$ CKD patients to $76 \%$ in stage 5 CKD patients due to the drastic reduction in renal erythropoietin production [4]. The current guidelines [5] specify that erythropoietin stimulating agent (ESA) therapy in dialysis patients should be initiated to avoid hemoglobin (Hgb) levels $<9.0 \mathrm{~g} / \mathrm{dL}$, while for non-dialysis dependent CKD patients ESA therapy should be individualized depending on the rate of $\mathrm{Hgb}$ decline if levels are below $10.0 \mathrm{~g} / \mathrm{dL}$. When individualizing ESA therapy in CKD patients, benefits such as potential reduction of blood transfusions should be weighed against risks such as hypertension, stroke, or vascular access loss. Additional potential benefits from correcting anemia may also include delaying progression of CKD [6], leading to a regression of left ventricular hypertrophy [7-9] and improvement in patients' quality of life $[10,11]$. Fink et al. [12] studied the impact of ESA administration prior to dialysis on post-dialysis initiation survival and found that pre-dialysis ESA was associated with lower mortality risk during the first 19 months after transition. In a cohort of patients on ESA therapy prior to dialysis initiation, Kataoka et al. [13] reported that Hgb levels below $8 \mathrm{~g} / \mathrm{dL}$ at the time of hemodialysis initiation were associated with a higher incidence of CV and cerebrovascular events compared to Hgb levels $\geq 8 \mathrm{~g} / \mathrm{dL}$. Although a meta-analysis of several studies has cautioned that treating to "normalized" $\mathrm{Hgb}$ ranges may not improve survival [14] and that a rapid increase in Hgb levels in a short period of time may also lead to adverse outcomes $[15,16]$, a rapid decline in $\mathrm{Hgb}$ has also been associated with higher risk of mortality and CV events [17].
To date, there are no studies that have investigated associations of both Hgb levels and its changes (slope) prior to ESRD initiation with post-ESRD outcomes. Thus, we sought to examine the association of pre-ESRD Hgb values and $\mathrm{Hgb}$ changes expressed as slope with early postESRD hospitalization rate, $\mathrm{CV}$, and all-cause mortality in a contemporary cohort of veterans.

\section{Methods}

\section{Study Population and Data Source}

The analytical cohort was derived from the United States Renal Data System (USRDS) Special Study Center Transition of Care in CKD, which aimed to investigate incident ESRD US veterans who transitioned to ESRD between October 1, 2007 and March 30, 2014 [18-23]. Of the original population of 85,505 veterans derived from USRDS records, we excluded patients without data on follow-up $(n=1,958)$ and with missing date of birth $(n=3)$. Finally, we excluded 52,072 patients who did not have Hgb measured in the 6 months prior to the transition to ESRD. Thus, our final analytical cohort consisted of 31,472 incident ESRD patients (online suppl. Fig. S1; for all online suppl. material, see www.karger.com/ doi/10.1159/000489223). In additional analysis examining the association of pre-ESRD Hgb slopes with outcomes, we further excluded an additional 6,773 patients who did not meet the slope criteria of $\geq 2 \mathrm{Hgb}$ measurements at least 90 days apart during the 1 -year pre-ESRD (prelude) period, thereby resulting in an analytical sub cohort of 24,699 patients. Given the nonintrusive nature, patient anonymity, and large sample size, the requirement for written informed consent was waived and the study was approved by the Memphis and Long Beach Veterans Affairs (VA) Medical Centers Institutional Review Boards.

\section{Demographic, Clinical, and Laboratory Measurements}

Patient characteristics collected at baseline were extracted from a composite of USRDS, VA, and Centers for Medicare and Medicaid Services (CMS) databases. Data on marital status were obtained from the VA records only. Data on the primary cause of ESRD and access type at dialysis initiation were collected from USRDS records only. VA and CMS data were used to determine the preexisting comorbidity status and Charlson Comorbidity Index (CCI). Prescription medication information was extracted from CMS Medicare Part D and VA pharmacy dispensation records. Medication use in this study was defined as ever having a prescription filled during the baseline period, 6 months prior to ESRD transition.

Most laboratory measurements, including serum Hgb, were obtained from the VA Decision Support System National Data Extracts Laboratory Results file. Serum ferritin was extracted from the VA Corporate Data Warehouse (CDW) LabChem file. Data on serum creatinine were chiefly extracted from USRDS records of the CMS 2728 form, and supplemented with data from the VA CDW LabChem file. Estimated glomerular filtration rate (eGFR) at transition was calculated from serum creatinine according to the Chronic Kidney Disease Epidemiology Collaboration equation [24]. Finally, body mass index (BMI) and blood pressure data were obtained from the VA CDW Vital Signs file. With the exception of 
the last eGFR prior to transition, all laboratory measurements during the 6-month period prior to ESRD transition were averaged into a single measurement and used as baseline levels. Kidney function decline, expressed by eGFR slope, was calculated using a mixed-effects (random intercept and slope) model in patients with $\geq 2$ eGFR measurements at least 90 days apart during the 1-year pre-ESRD period, and included at least one measurement in the 6-month prelude period [21].

\section{Exposure Measurement}

The main exposure of this study was pre-ESRD (prelude) Hgb. Baseline prelude Hgb levels were averaged over 6 months prior to transition and were categorized into 5 groups: $(1)<9.0$, (2) $9.0-<$ 10.0 , (3) $10.0-<11.0$, (4) $11.0-<12.0$, and (5) 12 or more g/dL. Among a subset of these patients, we also calculated the Hgb slope over the 1-year period prior to transition using a mixed-effects model. We then categorized Hgb slope into 5 groups: $(1) \leq-3.0,(2)>-3.0$ to $\leq-2.0,(3)>-2.0$ to $\leq-1.0,(4)>-1.0$ to $\leq 0$, and $(5)>0 \mathrm{~g} / \mathrm{dL} /$ year.

\section{Outcome Assessment}

The main outcomes of interest were post-ESRD 12-month allcause mortality, 12-month CV mortality, and 12-month hospitalization rate. CV causes of death were extracted from USRDS records. Information on all outcomes and censoring events were obtained from VA, CMS, and USRDS records. Patients were followed from the initiation of ESRD and until death, kidney transplantation, loss to follow-up, or the date of final follow-up for all patients (12 months post-ESRD or September 2, 2014 for all-cause mortality and June 30, 2014 for CV mortality).

\section{Statistical Analysis}

Patient demographic and clinical characteristics are presented as means $\pm \mathrm{SD}$, median (interquartile range [IQR]), or percent as appropriate for the total cohort and stratified by $\mathrm{Hgb}$ groups.

To examine trajectories of monthly averaged Hgb 1-year preand post-transition, we used a mixed-effects regression model and stratified trajectories by the baseline Hgb group.

Cox proportional hazard models were used to evaluate the association of $\mathrm{Hgb}$ (baseline, or slope) with all-cause and CV mortality. Finally, the relationship of $\mathrm{Hgb}$ (baseline, or slope) with 12-month hospitalization rates was evaluated using negative binomial regression models.

For each outcome, 4 hierarchal models of adjustment were used: (i) unadjusted; (ii) case-mix: age, gender, race, ethnicity, marital status, CCI, atrial fibrillation, hyperlipidemia, ischemic heart disease, myocardial infarction, congestive heart failure, peripheral vascular disease, cerebrovascular disease, chronic obstructive pulmonary disease, peptic ulcer disease, liver disease, diabetes mellitus, cancer, and primary cause of ESRD; (iii) casemix + malnutrition inflammation complex syndrome (MICS): which included all covariates in the case-mix model plus last eGFR prior to transition and baseline laboratory measures of bicarbonate, albumin, calcium, phosphorus, white blood cell count, alkaline phosphatase, BMI, and ever use of oral or intravenous (IV) iron and ESA in the 6-month pre-ESRD period. For the slope analyses, we further adjusted for the last available $\mathrm{Hgb}$ measurement in the 1 -year period prior to ESRD transition as a covariate in all models. Finally, an additional model (iv) was included in slope analyses, which adjusted for covariates from the case-mix and MICS model with further adjustment for eGFR slope.
We defined the case-mix + MICS adjustment and the case-mix + MICS + last Hgb + eGFR slope adjustment as the primary models of interest for the baseline and slope analyses respectively. In sensitivity analyses, we examined the baseline Hgb-mortality relationship in subgroup analyses across strata of clinical characteristics, and in analyses modeling $\mathrm{Hgb}$ and $\mathrm{Hgb}$ slope as a continuous variable using restricted cubic splines with knots at the 5th, 35th, 65 th, and 95th percentiles.

There were $<0.2$ and $3 \%$ of missing data on demographics and medications, respectively, and were handled using missing categories. Laboratory measurements used in analyses were missing on an average, $13 \%$ of the patients and were imputed with means. All analyses were conducted using SAS Enterprise Guide, version 7.1 (Cary, NC, USA) and STATA version 14.2 (StataCorp, College Station, TX, USA).

\section{Results}

\section{Baseline Demographic, Clinical, and Laboratory Characteristics}

A total of 31,472 US veterans transitioning to ESRD were included in this study. The cohort was on average $68 \pm 11$ years old and included $2 \%$ female and $30 \%$ African-American patients, as well as $47 \%$ patients with diabetes mellitus as the primary cause of ESRD and 69\% who initiated ESRD with a central venous catheter (Table 1). In the 6 months prior to transition to ESRD, patients had a (mean \pm SD) Hgb of $10.6 \pm 1.6 \mathrm{~g} / \mathrm{dL}$. Patients with lower Hgb were more likely to be younger, AfricanAmerican and not married; and had lower prevalence of $\mathrm{CV}$ disease including myocardial infarction, congestive heart failure, peripheral vascular disease, ischemic heart disease, and cerebrovascular disease (Table 1). Moreover, lower Hgb patients were more likely to have lower levels of BMI, serum bicarbonate and calcium, yet higher measurements of blood urea nitrogen and systolic blood pressure. Finally, patients with a low level of Hgb were more likely to have prescriptions for ESA and oral or IV iron in the 6-months prior to transition.

\section{6-Month Averaged Pre-ESRD Hgb and 12-Month Post-ESRD Mortality}

During the first 12-months of ESRD, 7,198 patients died with a crude rate of 27.5 deaths $(26.9,28.2)$ per 100 person-years. Patients with $\mathrm{Hgb} 10-<11 \mathrm{~g} / \mathrm{dL}$ had the lowest rate of 12-month all-cause mortality. After adjustment for demographics and comorbid conditions, there was a U-shaped association between baseline Hgb and 12-month all-cause mortality (reference $\mathrm{Hgb} 10-<11 \mathrm{~g} /$ dL; online suppl. Table 1a; Fig. 1a). Moreover, after adjustment for laboratory parameters as well as medica- 
Table 1. Baseline characteristics of 31,472 veterans transitioning to ESRD stratified by 6-month pre-ESRD hemoglobin

\begin{tabular}{|c|c|c|c|c|c|c|}
\hline & \multirow[t]{2}{*}{ Total } & \multicolumn{5}{|c|}{ 6-Month pre-ESRD Hgb strata, g/dL } \\
\hline & & $<9$ & $9-<10$ & $10-<11$ & $11-<12$ & $\geq 12$ \\
\hline$n(\%)$ & 31,472 & $4,637(14.8)$ & $7,342(23.3)$ & $8,078(25.7)$ & $5,705(18.1)$ & $5,710(18.1)$ \\
\hline \multicolumn{7}{|l|}{ Demographics } \\
\hline Age, years & $68 \pm 11$ & $65 \pm 11$ & $68 \pm 11$ & $69 \pm 11$ & $69 \pm 11$ & $69 \pm 11$ \\
\hline \multicolumn{7}{|l|}{ Gender, \% } \\
\hline Female & 2 & 2 & 2 & 2 & 2 & 1 \\
\hline \multicolumn{7}{|l|}{ Race, $\%$} \\
\hline White & 65 & 48 & 60 & 66 & 71 & 77 \\
\hline African-American & 30 & 47 & 34 & 29 & 25 & 19 \\
\hline Other & 5 & 5 & 5 & 5 & 5 & 4 \\
\hline \multicolumn{7}{|l|}{ Ethnicity, \% } \\
\hline Hispanic & 8 & 8 & 8 & 8 & 7 & 7 \\
\hline \multicolumn{7}{|l|}{ Marital status, \% } \\
\hline Single & 9 & 13 & 9 & 8 & 7 & 7 \\
\hline Married & 53 & 43 & 51 & 55 & 57 & 59 \\
\hline Divorced & 27 & 34 & 29 & 26 & 25 & 25 \\
\hline Widowed & 11 & 10 & 11 & 11 & 10 & 10 \\
\hline \multicolumn{7}{|l|}{ Primary cause of ESRD, \% } \\
\hline Diabetes & 47 & 47 & 50 & 49 & 46 & 39 \\
\hline Hypertension & 28 & 26 & 26 & 29 & 30 & 30 \\
\hline Glomerulonephritis & 6 & 6 & 6 & 6 & 6 & 6 \\
\hline Cystic kidney disease & 1 & 1 & 1 & 1 & 2 & 2 \\
\hline Other/unknown cause & 18 & 20 & 17 & 15 & 16 & 22 \\
\hline Charlson comorbidity index & $4(2-5)$ & $3(2-5)$ & $4(2-5)$ & $4(2-5)$ & $4(2-6)$ & $3(2-5)$ \\
\hline \multicolumn{7}{|l|}{ Comorbid conditions, $\%$} \\
\hline Anemia & 69 & 77 & 77 & 74 & 68 & 50 \\
\hline Atrial fibrillation & 14 & 10 & 14 & 14 & 15 & 17 \\
\hline Depression & 26 & 26 & 27 & 25 & 25 & 25 \\
\hline Hyperlipidemia & 78 & 69 & 77 & 80 & 81 & 81 \\
\hline Ischemic heart disease & 54 & 44 & 53 & 56 & 57 & 58 \\
\hline Myocardial infarction & 23 & 16 & 22 & 24 & 25 & 27 \\
\hline Congestive heart failure & 51 & 48 & 53 & 51 & 50 & 49 \\
\hline Peripheral vascular disease & 34 & 28 & 34 & 36 & 36 & 36 \\
\hline Cerebrovascular disease & 28 & 23 & 28 & 29 & 30 & 29 \\
\hline Chronic pulmonary disease & 38 & 32 & 39 & 39 & 39 & 42 \\
\hline Peptic ulcer disease & 6 & 6 & 6 & 6 & 6 & 5 \\
\hline Diabetes & 69 & 69 & 72 & 71 & 69 & 63 \\
\hline Liver disease & 11 & 13 & 12 & 10 & 10 & 10 \\
\hline Cancer & 22 & 21 & 22 & 22 & 22 & 22 \\
\hline Bleeding disorders & 26 & 23 & 25 & 26 & 26 & 28 \\
\hline \multicolumn{7}{|l|}{ Initial access type, $\%$} \\
\hline AV fistula/AV graft & 22 & 18 & 22 & 27 & 25 & 17 \\
\hline Catheter & 69 & 75 & 70 & 64 & 65 & 72 \\
\hline Other/unknown & 9 & 7 & 8 & 9 & 11 & 11 \\
\hline \multicolumn{7}{|l|}{ 6-Month averaged laboratory measures } \\
\hline Bicarbonate, mEq/L & $23.0 \pm 4.0$ & $21.4 \pm 3.9$ & $22.4 \pm 3.7$ & $22.8 \pm 3.7$ & $23.4 \pm 3.9$ & $24.7 \pm 4.0$ \\
\hline Potassium, mEq/L & $4.5 \pm 0.5$ & $4.5 \pm 0.6$ & $4.5 \pm 0.5$ & $4.5 \pm 0.5$ & $4.5 \pm 0.6$ & $4.4 \pm 0.5$ \\
\hline Blood urea nitrogen, $\mathrm{mg} / \mathrm{dL}$ & $62.5 \pm 23.4$ & $71.7 \pm 25.3$ & $66.3 \pm 21.4$ & $64.5 \pm 21.4$ & $60.3 \pm 21.6$ & $49.4 \pm 23.3$ \\
\hline White blood cell count, $\times 10^{3} / \mu \mathrm{L}$ & $7.8 \pm 3.1$ & $7.7 \pm 3.8$ & $7.8 \pm 3.3$ & $7.7 \pm 2.7$ & $7.7 \pm 2.8$ & $8.2 \pm 3.1$ \\
\hline Alkaline phosphatase, U/L & $84(66-110)$ & $83(64-109)$ & $85(66-112)$ & $83(65-109)$ & $84(66-110)$ & $84(67-109)$ \\
\hline Albumin, g/dL & $3.4 \pm 0.6$ & $3.1 \pm 0.6$ & $3.2 \pm 0.6$ & $3.4 \pm 0.6$ & $3.5 \pm 0.6$ & $3.6 \pm 0.6$ \\
\hline Calcium, mg/dL & $8.7 \pm 0.7$ & $8.3 \pm 0.8$ & $8.5 \pm 0.7$ & $8.7 \pm 0.7$ & $8.9 \pm 0.7$ & $9.0 \pm 0.7$ \\
\hline Phosphorous, mg/dL & $5.1 \pm 1.3$ & $5.6 \pm 1.5$ & $5.2 \pm 1.3$ & $5.1 \pm 1.2$ & $4.9 \pm 1.2$ & $4.7 \pm 1.2$ \\
\hline Ferritin, ng/mL & $199(106-367)$ & $246(122-447)$ & $219(116-398)$ & $189(104-338)$ & $173(96-311)$ & $144(82-285)$ \\
\hline Body mass index, $\mathrm{kg} / \mathrm{m}^{2}$ & $29.9 \pm 6.6$ & $29.2 \pm 6.7$ & $29.7 \pm 6.7$ & $29.8 \pm 6.5$ & $30.2 \pm 6.6$ & $30.7 \pm 6.7$ \\
\hline Systolic blood pressure, $\mathrm{mm} \mathrm{Hg}$ & $142 \pm 18$ & $146 \pm 18$ & $143 \pm 17$ & $142 \pm 18$ & $141 \pm 18$ & $139 \pm 19$ \\
\hline Diastolic blood pressure, $\mathrm{mm} \mathrm{Hg}$ & $74 \pm 11$ & $75 \pm 12$ & $73 \pm 11$ & $73 \pm 11$ & $74 \pm 12$ & $75 \pm 12$ \\
\hline
\end{tabular}


Table 1. (continued)

\begin{tabular}{|c|c|c|c|c|c|c|}
\hline & \multirow[t]{2}{*}{ Total } & \multicolumn{5}{|c|}{ 6-Month pre-ESRD Hgb strata, g/dL } \\
\hline & & $<9$ & $9-<10$ & $10-<11$ & $11-<12$ & $\geq 12$ \\
\hline Last eGFR prior to transition, $\mathrm{mL} / \mathrm{min} / 1.73 \mathrm{~m}^{2}$ & $9.7(7.1-13.2)$ & $8.4(5.9-11.8)$ & $9.4(6.8-12.7)$ & $9.6(7.1-12.9)$ & $10.1(7.5-13.5)$ & $10.9(7.9-15.6)$ \\
\hline \multicolumn{7}{|l|}{$\begin{array}{l}\text { Medication use in the } 6 \text { months prior to } \\
\text { transition, \% }\end{array}$} \\
\hline ESA & 32 & 51 & 47 & 34 & 19 & 5 \\
\hline Iron & 39 & 59 & 53 & 40 & 28 & 13 \\
\hline
\end{tabular}

Data presented as mean $\pm \mathrm{SD}$, median (IQR), or proportion where appropriate.

ESRD, end-stage renal disease; Hgb, hemoglobin; AV, arteriovenous; eGFR, estimated glomerular filtration rate; ESA, erythropoietin stimulating agents; IQR, interquartile range.

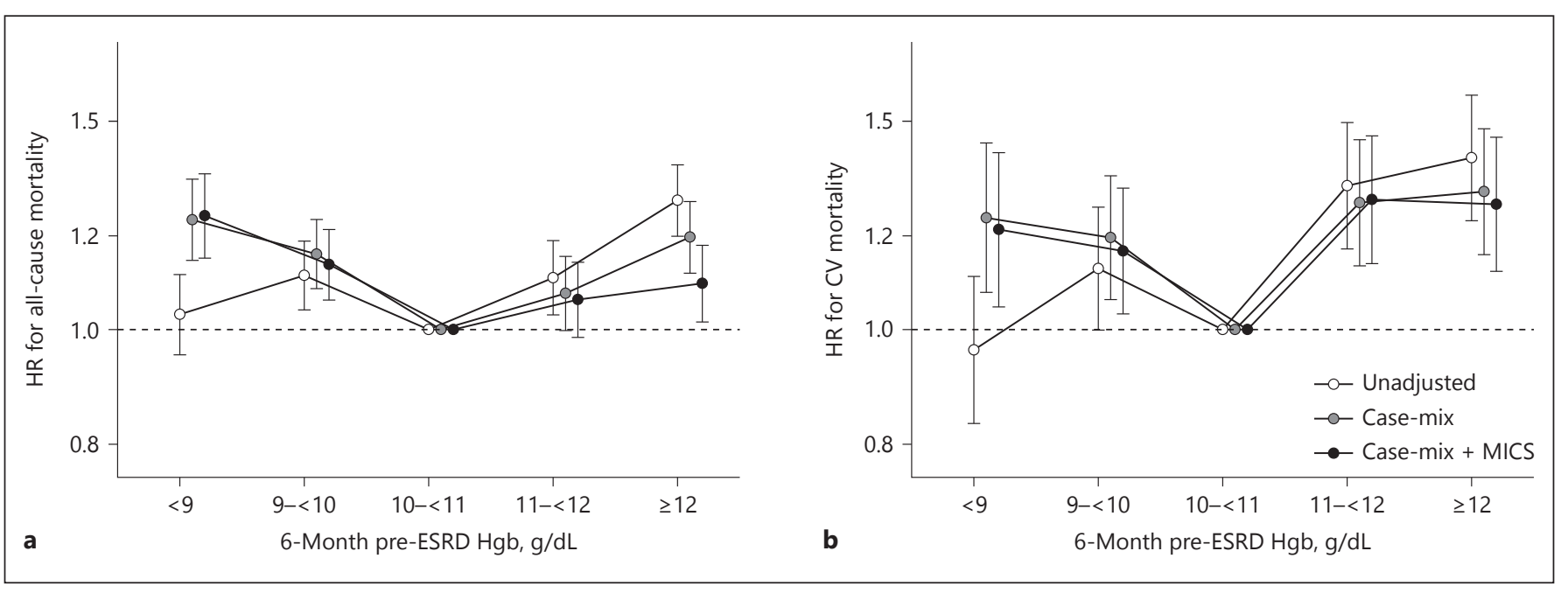

Fig. 1. Association of 6-month pre-end-stage renal disease (ESRD) hemoglobin (Hgb) with (a) 12-month all-cause mortality and (b) 12 -month cardiovascular mortality in 31,472 veterans transitioning to ESRD.

tions, this U-shaped relationship persisted but was slightly attenuated for associations of higher $\mathrm{Hgb}$ with higher mortality risk. $\mathrm{Hgb}<9 \mathrm{~g} / \mathrm{dL}$ was associated with $25 \%$ higher mortality risk after full adjustment compared to Hgb $10-<11$ g/dL (HR [95\% CI] 1.25 [1.15-1.35]). Moreover, in restricted cubic spline analysis, lower $\mathrm{Hgb}<10 \mathrm{~g} /$ $\mathrm{dL}$ was associated with higher mortality after full adjustment, though higher $\mathrm{Hgb} \geq 11 \mathrm{~g} / \mathrm{dL}$ trended toward higher all-cause mortality risk (online suppl. Fig. S2a). Finally, low $\mathrm{Hgb}<10 \mathrm{~g} / \mathrm{dL}$ was associated with higher early allcause mortality across most strata of clinical characteristics and laboratory measurements (ref: Hgb $10-<11 \mathrm{~g} /$ $\mathrm{dL}$ ), while higher $\mathrm{Hgb} \geq 11 \mathrm{~g} / \mathrm{dL}$ trended toward higher mortality risk though attenuated in some strata (online suppl. Fig. S3). There were significant interactions on the basis of prior congestive heart failure, cerebrovascular disease, diabetes, and higher $\mathrm{CCI} \geq 4$, whereas lower $\mathrm{Hgb}$ $<10 \mathrm{~g} / \mathrm{dL}$ was associated with a higher risk of mortality among patients without said comorbidities. There was no interaction on the basis of hematological conditions or use of ESA or iron medications.

Baseline Hgb concentrations also exhibited a similar U-shaped association with 12-month CV mortality after adjustment for clinical characteristics (online suppl. Table S1b; Fig. 1b). Patients with Hgb $11-<12$ and $\geq 12$ $\mathrm{g} / \mathrm{dL}$ had the highest risk of early $\mathrm{CV}$ mortality (HR [95\% CI] 1.29 [1.14-1.46] and 1.28 [1.12-1.45], respectively), (ref: Hgb $10-<11 \mathrm{~g} / \mathrm{dL}$ ). In restricted cubic spline analysis, continuous Hgb largely exhibited a Ushaped relationship with $\mathrm{CV}$ mortality, though it was modestly attenuated after full adjustment (online suppl. Fig. S2b). 


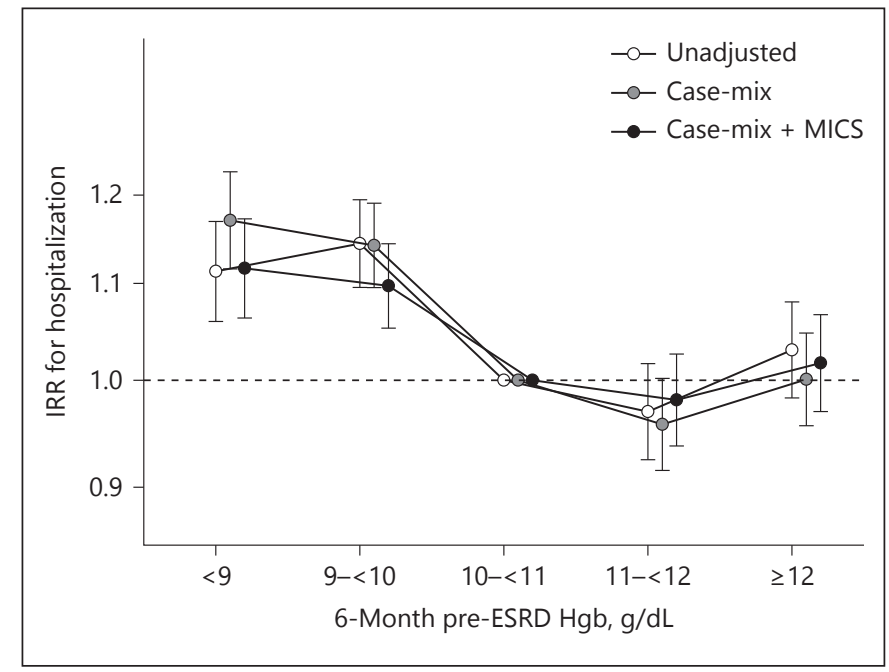

Fig. 2. Association of 6-month pre-end stage renal disease (ESRD) hemoglobin (Hgb) with 12-month hospitalization count in 31,472 veterans transitioning to ESRD. IRR, incidence rate ratio.

\section{6-Month Averaged Pre-ESRD Hgb and 12-Month Post-ESRD Hospitalization}

Overall, the patients had a median (IQR) of $1(0-3)$ hospitalizations in the first 12 months after progression to ESRD. Across all levels of adjustment, compared to Hgb $10-<11$ g/dL, lower baseline Hgb levels $(<10$ g/dL) were associated with higher hospitalization rates (online suppl. Table S2; Fig. 2). In contrast, higher Hgb levels $(\geq 11 \mathrm{~g} / \mathrm{dL})$ were not associated with hospitalization incidence. In this cohort, the most common cause (listed primary diagnosis) of hospitalization after transitioning to ESRD was dialysis access complications, where patients with $\mathrm{Hgb}<9 \mathrm{~g} / \mathrm{dL}$ had the highest rate of this diagnosis. Hospitalization rates for nonhypertensive congestive heart failure were highest among patients with $\mathrm{Hgb} \geq 12 \mathrm{~g} /$ dL (online suppl. Table S3).

\section{Hgb Trajectories Before and After ESRD Transition}

In the prelude period, all baseline Hgb groups showed a gradual decreasing trend when approaching transition to ESRD (Fig. 3). However, patients with a lower prelude 6-month averaged baseline $\mathrm{Hgb}(<10 \mathrm{~g} / \mathrm{dL})$ had the steepest decline before ESRD initiation. Within the first few months after ESRD initiation, all Hgb groups were rapidly corrected toward $11-12 \mathrm{~g} / \mathrm{dL}$ with a reduction in variation across groups in the post-ESRD period. Though the overall variations between the Hgb groups were vastly attenuated after ESRD initiation, the hierarchical order was maintained through the first year of ESRD.

\section{2-Month Pre-ESRD Slope in Hgb and 12-Month}

\section{Post-ESRD Mortality and Hospitalization}

To further examine trajectories of pre-ESRD $\mathrm{Hgb}$, slopes were calculated in 24,699 patients ( $78 \%$ of the baseline cohort). The median (IQR) rate of change in preESRD Hgb was -1.6 (-2.6 to -0.7$) \mathrm{g} / \mathrm{dL} /$ year. Patients with the steepest decline were younger, had a lower prevalence of comorbid conditions, including diabetes and congestive heart failure, had a steeper eGFR slope, and were less likely to be treated with ESA or iron (online suppl. Table S4).

After adjustment for clinical conditions, laboratory parameters and final $\mathrm{Hgb}$, patients with the steepest $\mathrm{Hgb}$ decline ( $\leq-3 \mathrm{~g} / \mathrm{dL} /$ year $)$ had the highest risk of 12 -month all-cause mortality compared to a moderate decline in Hgb (>-2 to $\leq-1$ g/dL/year) (HR [95\% CI] 1.10 [1.011.19]; online suppl. Table S5a; Fig. 4a). However, this association was attenuated to the null after additional adjustment for eGFR slope. A similar relationship was observed between the $\mathrm{Hgb}$ slope and CV mortality. The steepest $\mathrm{Hgb}$ decline $(\leq-3 \mathrm{~g} / \mathrm{dL} /$ year) was associated with the highest risk of CV mortality (HR [95\% CI] 1.17 [1.011.36]), yet this relationship was again attenuated after further eGFR slope adjustment (online suppl. Table S5b; Fig. 4b). In restricted cubic spline analyses, the relationship of Hgb slope with all-cause mortality showed a comparable attenuated relationship. However, the association between Hgb slope with CV mortality trended toward a U-shaped association, after full adjustment including eGFR slope (online suppl. Fig. S4a, b).

Finally, we observed a U-shaped association with $\mathrm{Hgb}$ slope and early post-ESRD hospitalization rate after adjustment for case-mix and MICS covariates (online suppl. Table S6; Fig. 5a). After further adjustment for eGFR slope, the association attenuated to a modest J-shape, where a steep decline in $\mathrm{Hgb}$ trended toward a higher hospitalization rate (incidence rate ratio [95\% CI] 1.05 [0.99-1.10]). However, a rise in $\mathrm{Hgb}$ was associated with a higher hospitalization incidence after full adjustment, compared to a moderate $\mathrm{Hgb}$ decline ( $>-2$ to $\leq-1 \mathrm{~g} / \mathrm{dL} /$ year; incidence rate ratio [95\% Cl] 1.10 [1.04-1.16]).

\section{Discussion}

In our cohort of 31,472 veteran patients transitioning to ESRD, we observed a U-shaped association between pre-ESRD Hgb and 12-month post-ESRD all-cause and $\mathrm{CV}$ mortality, in which low $\mathrm{Hgb}<9 \mathrm{~g} / \mathrm{dL}$ and high $\mathrm{Hgb}$ $\geq 12 \mathrm{~g} / \mathrm{dL}$ demonstrate the highest risks. Moreover, lower 
Fig. 3. Trajectories of monthly averaged hemoglobin (Hgb) 12-months pre- and post-transition to ESRD stratified by 6-month averaged pre-ESRD hemoglobin groups.

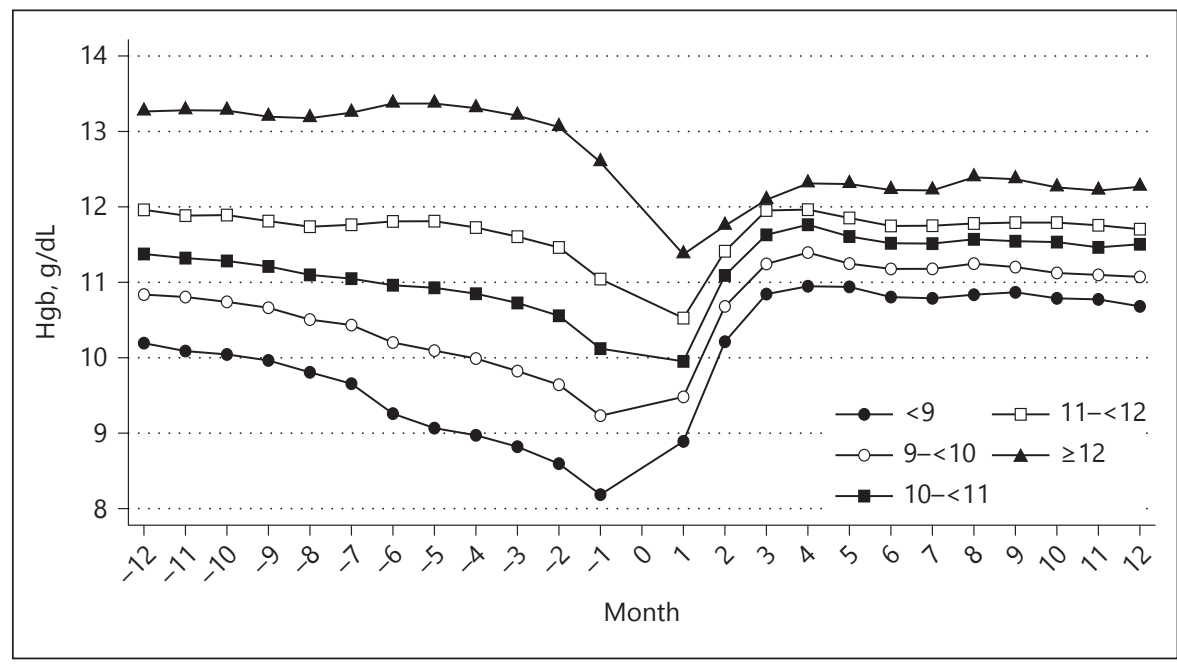

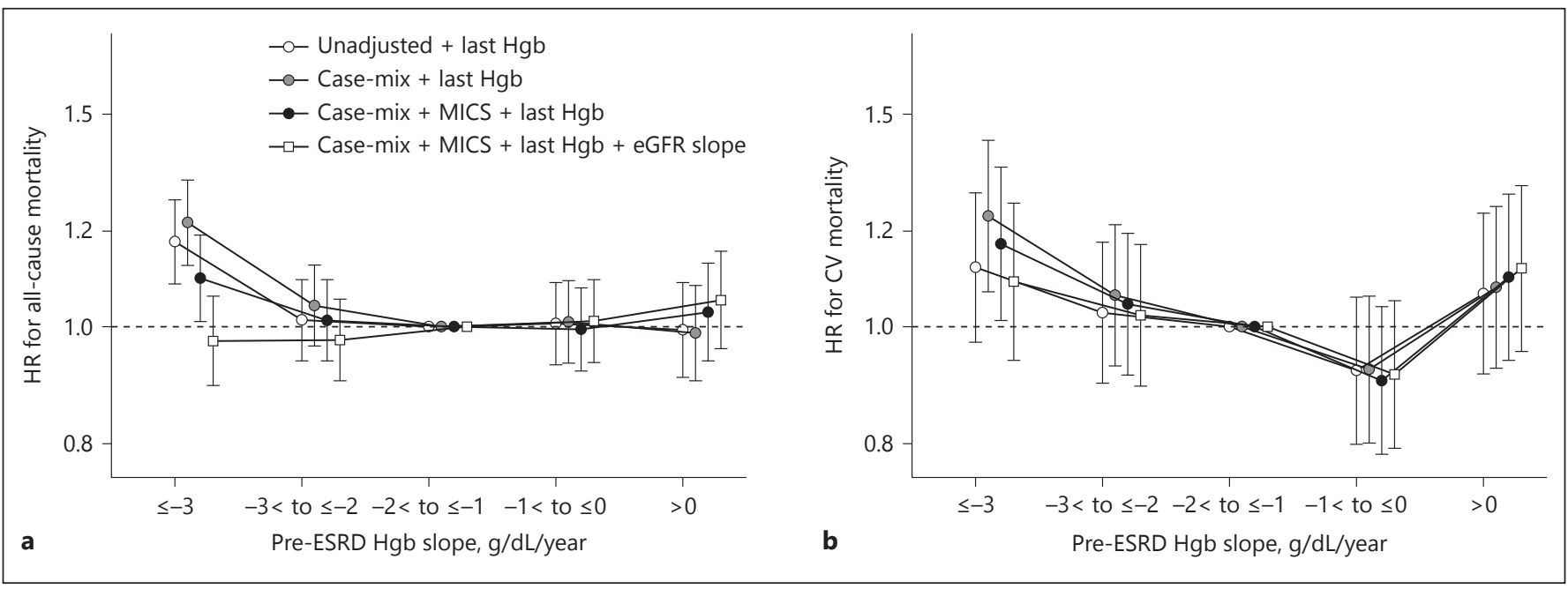

Fig. 4. Association of pre-end-stage renal disease (ESRD) hemoglobin (Hgb) slope with (a) 12-month all-cause mortality and (b) 12 -month cardiovascular mortality across levels of adjustment in 24,699 veterans transitioning to ESRD.

pre-ESRD Hgb was associated with higher hospitalization rates. However, neither a decline nor an increase in Hgb slope in the 1 year prior to transition to ESRD was associated with all-cause or CV mortality in the fully adjusted model, including adjustment for kidney function decline. Nevertheless, an increased Hgb slope in the 1 year prior to transition to ESRD was associated with higher hospitalization rates even after adjustment for eGFR slope.

The association between anemia and adverse outcomes has been well established. For instance, anemia is an independent risk factor for left ventricular hypertrophy, as well as morbidity and mortality from CV causes [25-27]. Although ESA therapy is indicated for anemia management, several clinical trials have suggested that treatment of anemia to "normalized" Hgb levels is associated with adverse outcomes in both dialysis and CKD patients [14, 28-30]. Therefore, current guidelines [5] advise against increasing $\mathrm{Hgb}$ levels above $13.0 \mathrm{~g} / \mathrm{dL}$. In the Correction of $\mathrm{Hgb}$ and Outcomes in Renal Insufficiency randomized clinical trial, non-dialysis dependent CKD patients reaching and maintaining Hgb concentrations of either 13.5 or $11.3 \mathrm{~g} / \mathrm{dL}$ with epoetin alpha were compared, and those randomized to the $13.5 \mathrm{~g} / \mathrm{dL}$ group suffered from more adverse events including death, myocardial infarction, and hospitalization for congestive heart failure or stroke, compared to patients in the $11.3 \mathrm{~g} / \mathrm{dL}$ arm [28]. In addition, a higher death risk for patients with 


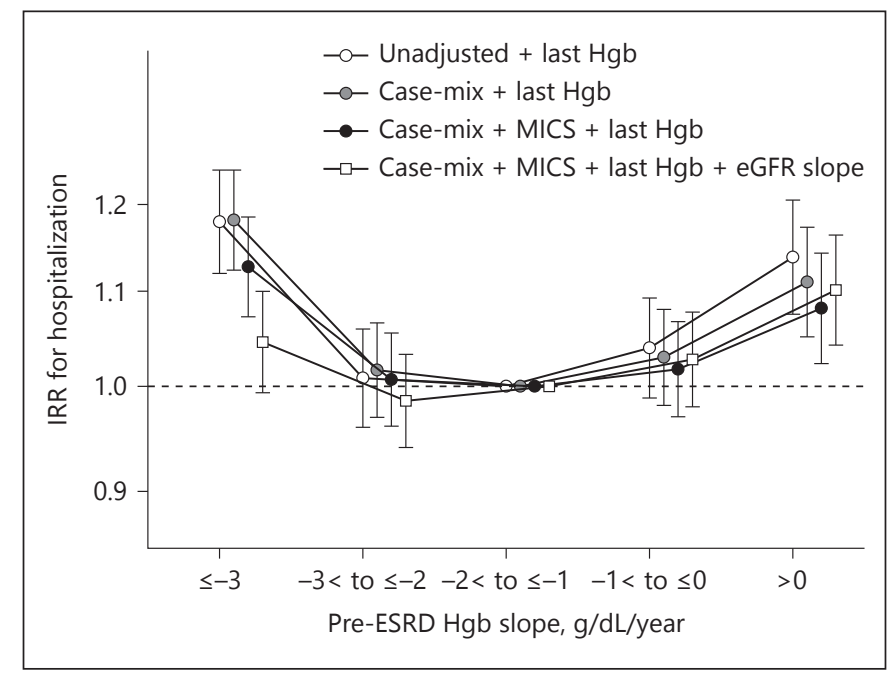

Fig. 5. Association of pre-end-stage renal disease (ESRD) hemoglobin (Hgb) slope with 12-month hospitalization count in 24,699 veterans transitioning to ESRD. IRR, incidence rate ratio.

$\mathrm{Hgb}>13.5 \mathrm{~g} / \mathrm{dL}$ compared to $11.5-<12.0 \mathrm{~g} / \mathrm{dL}$ has also been observed in a large cohort of hemodialysis patients. However, the death risk was even higher for patients with $\mathrm{Hgb}<10 \mathrm{~g} / \mathrm{dL}$ when compared to $11.5-<12.0 \mathrm{~g} / \mathrm{dL}$ [17]. Therefore, it might be inferred that "too low" Hgb levels could impose greater harm to patients than "too high" Hgb concentrations. Similarly, our observational data showed that pre-ESRD Hgb levels had a modest U-shaped association with post-ESRD mortality outcomes, where patients with pre-ESRD Hgb concentrations $<9 \mathrm{~g} / \mathrm{dL}$ had the highest all-cause and CV mortality risk and patients with $\mathrm{Hgb}$ values $\geq 12 \mathrm{~g} / \mathrm{dL}$ had a modestly higher risk of all-cause and CV mortality when compared to the reference group (Hgb: $10-<11 \mathrm{~g} / \mathrm{dL}$ ) in fully adjusted models. In our study, elevated pre-ESRD Hgb was not associated with higher hospitalization rates. However, when examining hospitalization causes, nonhypertensive congestive heart failure was more frequent in ESRD patients with prelude $\mathrm{Hgb} \geq 12 \mathrm{~g} / \mathrm{dL}$.

Kidney disease patients transitioning to dialysis-dependent CKD have a particularly high mortality risk within the first 6 months after the initiation of dialysis treatment compared to prevalent HD patients or renal transplant recipients $[18,31,32]$. Therefore, specialized pre-ESRD patient care, which focuses on factors that are commonly associated with adverse clinical events may improve post-ESRD outcomes. Since anemia is common sequelae of advanced CKD, we examined the association between changes in Hgb with early-ESRD outcomes. In our study, on average most patients exhibited a decline in $\mathrm{Hgb}$ during the 1 year prelude (pre-ESRD) period. The latter observation may have several important underlying causes that need to be considered. For instance, a decreasing $\mathrm{Hgb}$ slope may represent a faster decline in kidney function and/or deteriorating health status as CKD progresses. In addition, Hgb values are influenced by several different factors such as genetics [33], infection, inflammation [34, 35], and acute and chronic comorbidities [36]. Furthermore, medications such as angiotensin-converting enzyme inhibitors and angiotensin receptor blockers can also interfere with a patients' responsiveness to ESA treatment and subsequently impact Hgb levels [37]. In our study, neither a decline nor rise in Hgb slope in the 1 year prior to transition to ESRD was associated to higher all-cause or CV mortality after adjustment for eGFR slope.

However, a modest J-shaped association was observed between Hgb slope and higher hospitalization rates in fully adjusted models, where a rise in $\mathrm{Hgb}$ was associated with a $10 \%$ higher hospitalization incidence rate. Prior reviews have commented that increasing $\mathrm{Hgb}$ from ESA treatment results in increasing blood viscosity, resulting in increased viscosity-associated sheer stress, which in turn might then lead to thromboembolism $[38,39]$. These factors may be of particular relevance in patients with $\mathrm{CKD}$ who are more likely to have atherosclerotic CV disease and a higher risk of poor CV outcomes. Although we adjusted for ESA and iron treatment in fully adjusted models, a residual effect of these therapies on Hgb and blood viscosity may further confound the association between $\mathrm{Hgb}$ rise and hospitalization. A decline in $\mathrm{Hgb}$ was associated with higher hospitalization rates but was attenuated toward the null after adjustment for eGFR slope. As discussed above, Hgb decline may be related to a deteriorating health condition and consequent hospitalizations due to CKD progression.

Strengths of our study include the large veteran population size and ability to comprehensively capture data on comorbidity status and medication prescriptions in the pre-ESRD period. In addition, given the availability of repeated measures, we were able to calculate the change in $\mathrm{Hgb}$ prior to transition. However, several limitations of our study should be noted. First, due to the observational study design, we cannot make any decisive claims about the causal associations between $\mathrm{Hgblevels}$ or the rate of $\mathrm{Hgb}$ change with mortality and hospitalizations. It is also important to note that we are unable to completely exclude sources of residual confounding by variables that were not measured and were not included in the analysis cohort such as in- 
flammatory status, number of blood transfusions, and frequent acute events such as bleeding or hospitalization. Moreover, slopes were calculated using linearity assumptions and may be affected by acute episodes of anemia (e.g. blood loss, hospitalizations), which could also explain the observed associations. Given that the source population consisted of US veterans, and primarily Veteran Affairs users who are predominately white and male, this study may not be externally valid to other populations.

In conclusion, we observed that both pre-ESRD Hgb $<10$ and $\geq 12 \mathrm{~g} / \mathrm{dL}$ are associated with higher all-cause and $\mathrm{CV}$ mortality, and low Hgb is associated with higher hospitalization rates. In our fully adjusted model, which included eGFR slope, neither a decline nor increase of the $\mathrm{Hgb}$ slope was associated with all-cause or CV mortality. However, a rise in $\mathrm{Hgb}$ in the 1 year prior to transition to ESRD with adjustments for the last Hgb value and eGFR slope was associated with higher hospitalization rates. Thus, treatment of anemia and achieving and maintaining an appropriate $\mathrm{Hgb}$ level prior to ESRD transition may be of value in improving early post-ESRD outcomes. Further studies are warranted to compare the effectiveness of different anemia management strategies in the late stages of CKD in improving clinical outcomes in the postESRD period.

\section{Acknowledgments}

The work in this manuscript has been performed with the support of the National Institute of Diabetes, Digestive and Kidney Disease of the National Institute of Health research grants U01DK102163. K.K.Z. is supported by K24-DK091419 as well as philanthropic grants from Mr. Harold Simmons, Mr. Louis Chang, Dr. Joseph Lee, and AVEO. The data reported here have been supplied by the United States Renal Data System. Support for VA/CMS data is provided by the Department of Veterans Affairs, Veterans Health Administration, Office of Research and Development, Health Services Research and Development, VA Information Resource Center (project nos.SDR 02-237 and 98-004).

Drs. Elani Streja, Csaba P. Kovesdy, Kamyar Kalantar-Zadeh are employees of the Department of Veterans Affairs. The interpretation and reporting of these data are the responsibility of the authors and in no way should be seen as official policy or interpretation of the Department of Veterans Affairs or the US government.

\section{Disclosure Statement}

K.K.-Z. has received honoraria and/or support from Abbott, Abbvie, Alexion, Amgen, American Society of Nephrology, AstraZeneca, Aveo, Chugai, DaVita, Fresenius, Genetech, Haymarket Media, Hospira, Kabi, Keryx, National Institutes of Health, National Kidney Foundation, Relypsa, Resverlogix, Sanofi, Shire, Vifor, and ZS-Pharma. C.P.K. received honoraria from Amgen, Astra-Zeneca and Keryx.

\section{References}

1 Babitt JL, Lin HY: Mechanisms of anemia in CKD. J Am Soc Nephrol 2012;23:1631-1634.

-2 Schmidt RJ, Dalton CL: Treating anemia of chronic kidney disease in the primary care setting: cardiovascular outcomes and management recommendations. Osteopath Med Prim Care 2007;1:14.

-3 Thorp ML, Johnson ES, Yang X, Petrik AF, Platt R, Smith DH: Effect of anaemia on mortality, cardiovascular hospitalizations and end-stage renal disease among patients with chronic kidney disease. Nephrology (Carlton) 2009; 14:240-246.

4 McClellan W, Aronoff SL, Bolton WK, Hood S, Lorber DL, Tang KL, Tse TF, Wasserman $\mathrm{B}$, Leiserowitz M: The prevalence of anemia in patients with chronic kidney disease. Curr Med Res Opin 2004;20:1501-1510.

5 KDIGO clinical practice guideline for anemia and chronic kidney disease. Kidney International Supplements 2012;2:283-287. http:// www.kdigo.org/clinical_practice_guidelines/ pdf/KDIGO-Anemia\%20GL.pdf.

-6 Kuriyama S, Tomonari H, Yoshida H, Hashimoto T, Kawaguchi Y, Sakai O: Reversal of anemia by erythropoietin therapy retards the progression of chronic renal failure, especially in nondiabetic patients. Nephron 1997;77: 176-185.
7 Cannella G, La Canna G, Sandrini M, Gaggiotti M, Nordio G, Movilli E, Mombelloni S, Visioli O, Maiorca R: Reversal of left ventricular hypertrophy following recombinant human erythropoietin treatment of anaemic dialysed uraemic patients. Nephrol Dial Transplant 1991;6:31-37.

-8 Hayashi T, Suzuki A, Shoji T, Togawa M, Okada N, Tsubakihara Y, Imai E, Hori M: Cardiovascular effect of normalizing the hematocrit level during erythropoietin therapy in predialysis patients with chronic renal failure. Am J Kidney Dis 2000;35:250-256.

-9 Portoles J, Torralbo A, Martin P, Rodrigo J, Herrero JA, Barrientos A: Cardiovascular effects of recombinant human erythropoietin in predialysis patients. Am J Kidney Dis 1997;29: 541-548.

$\checkmark 10$ Association between recombinant human erythropoietin and quality of life and exercise capacity of patients receiving haemodialysis. Canadian Erythropoietin Study Group. BMJ 1990;300:573-578.

11 Kimel M, Leidy NK, Mannix S, Dixon J: Does epoetin alfa improve health-related quality of life in chronically ill patients with anemia? Summary of trials of cancer, HIV/AIDS, and chronic kidney disease. Value Health 2008; 11 : $57-75$.
12 Fink J, Blahut S, Reddy M, Light P: Use of erythropoietin before the initiation of dialysis and its impact on mortality. Am J Kidney Dis 2001;37:348-355.

13 Kataoka H, Tsuchiya K, Naganuma T, Okazaki M, Komatsu M, Kimura T, Shiohira S, Kawaguchi H, Nitta K: Relationship between anaemia management at haemodialysis initiation and patient prognosis. Nephrology (Carlton) 2015;20(suppl 4):14-21.

14 Phrommintikul A, Haas SJ, Elsik M, Krum $\mathrm{H}$ : Mortality and target haemoglobin concentrations in anaemic patients with chronic kidney disease treated with erythropoietin: a meta-analysis. Lancet 2007;369:381-388.

$\checkmark 15$ Singh AK: The FDA's perspective on the risk for rapid rise in hemoglobin in treating CKD anemia: Quo Vadis. Clin J Am Soc Nephrol 2010;5:553-556.

16 Unger EF, Thompson AM, Blank MJ, Temple R: Erythropoiesis-stimulating agents - time for a reevaluation. NEngl J Med 2010;362:189-192.

-17 Regidor DL, Kopple JD, Kovesdy CP, Kilpatrick RD, McAllister CJ, Aronovitz J, Greenland S, Kalantar-Zadeh K: Associations between changes in hemoglobin and administered erythropoiesis-stimulating agent and survival in hemodialysis patients. J Am Soc Nephrol 2006;17:1181-1191. 
-18 Kalantar-Zadeh K, Kovesdy CP, Streja E, Rhee CM, Soohoo M, Chen JLT, Molnar MZ, Obi Y, Gillen D, Nguyen DV, Norris KC, Sim JJ, Jacobsen SS: Transition of care from pre-dialysis prelude to renal replacement therapy: the blueprints of emerging research in advanced chronic kidney disease. Nephrol Dial Transplant 2017;32(suppl 2):ii91-ii98.

19 Molnar MZ, Gosmanova EO, Sumida K, Potukuchi PK, Lu JL, Jing J, Ravel VA, Soohoo M, Rhee CM, Streja E, Kalantar-Zadeh K, Kovesdy CP: Predialysis cardiovascular disease medication adherence and mortality after transition to dialysis. Am J Kidney Dis 2016;68:609-618.

-20 Sumida K, Diskin CD, Molnar MZ, Potukuchi PK, Thomas F, Lu JL, Rhee CM, Streja E, Yamagata K, Kalantar-Zadeh K, Kovesdy CP: Pre-end-stage renal disease hemoglobin variability predicts post-end-stage renal disease mortality in patients transitioning to dialysis. Am J Nephrol 2017;46:397-407.

-21 Sumida K, Molnar MZ, Potukuchi PK, Thomas F, Lu JL, Jing J, Ravel VA, Soohoo M, Rhee CM, Streja E, Kalantar-Zadeh K, Kovesdy CP: Association of slopes of estimated glomerular filtration rate with postend-stage renal disease mortality in patients with advanced chronic kidney disease transitioning to dialysis. Mayo Clin Proc 2016; 91:196-207.

22 US renal Data System: USRDS 2017 Annual Data Report: Atlas of Chronic Kidney Disease and End Stage Renal Disease in the United States, Chapter 8: Transition of Care in Chronic Kidney Disease. Bethesda, National Institutes of Health, National Institute of Diabetes and Digestive and Kidney Diseases, 2017.

23 Obi Y, Park C, Soohoo M, Sumida K, Hamano T, Rhee CM, Kovesdy CP, Kalantar-Zadeh K,
Streja E: Association of pre-ESRD serum calcium with post-ESRD mortality among incident ESRD patients: a cohort study. J Bone Miner Res 2018, Epub ahead of print.

24 Levey AS, Stevens LA, Schmid CH, Zhang YL, Castro AF 3rd, Feldman HI, Kusek JW, Eggers P, Van Lente F, Greene T, Coresh J; CKDEPI: A new equation to estimate glomerular filtration rate. Ann Intern Med 2009;150: 604-612.

25 Levin A, Thompson CR, Ethier J, Carlisle EJ, Tobe S, Mendelssohn D, Burgess E, Jindal K, Barrett B, Singer J, Djurdjev O: Left ventricular mass index increase in early renal disease: impact of decline in hemoglobin. Am J Kidney Dis 1999;34:125-134.

26 Besarab A, Soman S: Anemia management in chronic heart failure: lessons learnt from chronic kidney disease. Kidney Blood Press Res 2005;28:363-371.

27 Eckardt KU: Managing a fateful alliance: anaemia and cardiovascular outcomes. Nephrol Dial Transplant 2005;20(suppl 6): vi16-vi20.

28 Singh AK, Szczech L, Tang KL, Barnhart H, Sapp S, Wolfson M, Reddan D; CHOIR Investigators: Correction of anemia with epoetin alfa in chronic kidney disease. N Engl J Med 2006;355:2085-2098.

29 Besarab A, Bolton WK, Browne JK, Egrie JC, Nissenson AR, Okamoto DM, Schwab SJ, Goodkin DA: The effects of normal as compared with low hematocrit values in patients with cardiac disease who are receiving hemodialysis and epoetin. N Engl J Med 1998;339: 584-590.

30 Drueke TB, Locatelli F, Clyne N, Eckardt KU, Macdougall IC, Tsakiris D, Burger HU, Scherhag A; CREATE Investigators: Normalization of hemoglobin level in patients with chronic kidney disease and anemia. N Engl J Med 2006;355:2071-2084.
31 Lukowsky LR, Kheifets L, Arah OA, Nissenson AR, Kalantar-Zadeh K: Patterns and predictors of early mortality in incident hemodialysis patients: new insights. Am J Nephrol 2012;35:548-558.

32 Robinson BM, Zhang J, Morgenstern $\mathrm{H}$, Bradbury BD, Ng LJ, McCullough KP, Gillespie BW, Hakim R, Rayner H, Fort J, Akizawa T, Tentori F, Pisoni RL: Worldwide, mortality risk is high soon after initiation of hemodialysis. Kidney Int 2014;85:158-165.

33 Thein SL, Menzel S: Discovering the genetics underlying foetal haemoglobin production in adults. Br J Haematol 2009;145:455-467.

-34 Kalantar-Zadeh K, McAllister CJ, Lehn RS, Lee GH, Nissenson AR, Kopple JD: Effect of malnutrition-inflammation complex syndrome on EPO hyporesponsiveness in maintenance hemodialysis patients. Am J Kidney Dis 2003;42:761-773.

35 Priyadarshi A, Shapiro JI: Erythropoietin resistance in the treatment of the anemia of chronic renal failure. Semin Dial 2006;19: 273-278.

36 Ebben JP, Gilbertson DT, Foley RN, Collins AJ: Hemoglobin level variability: associations with comorbidity, intercurrent events, and hospitalizations. Clin J Am Soc Nephrol 2006; 1:1205-1210

37 Ogawa T, Nitta K: Erythropoiesis-stimulating agent hyporesponsiveness in end-stage renal disease patients. Contrib Nephrol 2015;185: 76-86.

38 Fishbane S, Besarab A: Mechanism of increased mortality risk with erythropoietin treatment to higher hemoglobin targets. Clin J Am Soc Nephrol 2007;2:1274-1282.

39 Jeong SK, Cho YI, Duey M, Rosenson RS: Cardiovascular risks of anemia correction with erythrocyte stimulating agents: should blood viscosity be monitored for risk assessment? Cardiovasc Drugs Ther 2010;24:151-160. 